\title{
Does the age of pharmaceuticals matter? Undetectable hydrate seeds impact hydration behaviour.
}

\section{Electronic Supplementary Information}

Patricia A. Basford, ${ }^{a b}$ Leigh D. Connor, ${ }^{c}$ Paul T. Whiteside ${ }^{a}$ and Aurora J. Cruz-Cabeza. ${ }^{b}$

${ }^{a}$ Medicinal Sciences, Pfizer R\&D UK Ltd, Sandwich, CT13 9NJ (UK)

${ }^{\mathrm{b}}$ Department of Chemical Engineering and Analytical Science, University of Manchester, Manchester, M13 9PL (UK)

${ }^{\mathrm{c}}$ Diamond Light Source Ltd., Harwell Science \& Innovation Campus, Didcot, Oxfordshire, OX11 0DE

*Corresponding authors.Emails: pat.basford@pfizer.com and aurora.cruzcabeza@manchester.ac.uk

\section{Contents}



2. Determination of the Critical Water Activity .........................................................2

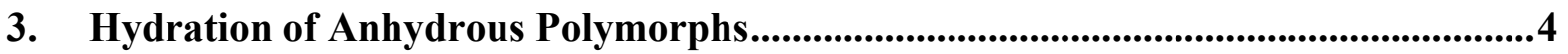

4. Powder X-ray Diffraction of Aged Samples ..........................................................9

4.1. High Resolution Synchrotron X-ray Powder Diffraction (HR-SXRPD) ............9

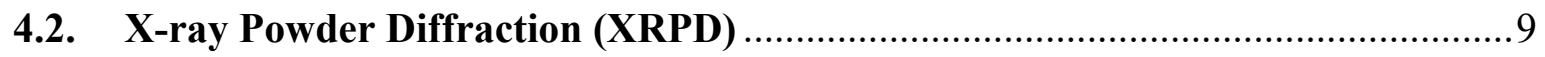

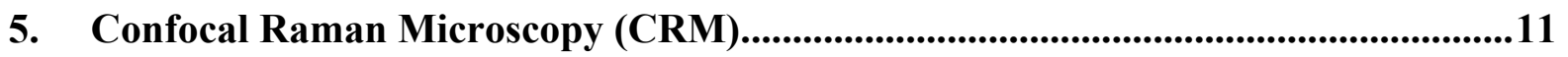

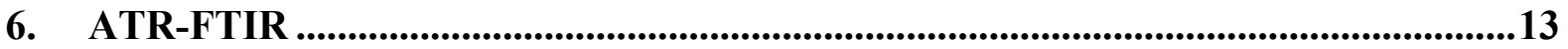

7. Activation Energy ......................................................................................................................14

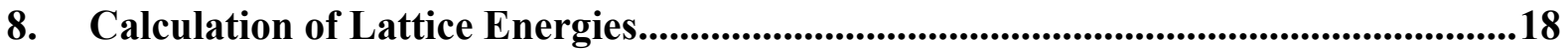

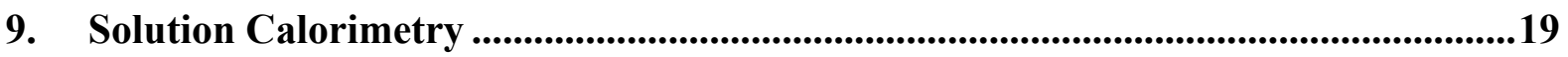

10. References............................................................................................................................21 


\section{Polymorphic forms.}

Given the variability in the naming convention of fluconazole polymorphs, found within the literature, we have continued to use our previously adopted naming convention ${ }^{1}$ based on the $\mathrm{CSD}^{2}$ refcodes. $\mathrm{MH}$ for the monohydrate form (IVUQIZ ${ }^{3}$ ), $\mathrm{AH}-\mathrm{A}$ for the triclinic polymorph $\left(\mathrm{IVUQOF}^{3}\right), \mathrm{AH}-\mathrm{B}$ for the thermodynamically stable $P 2_{1} / \mathrm{n}$ polymorph (IVUQOF $01^{4}$ ) and AH$\mathrm{C}$ for the $\mathrm{Pbca}$ polymorph (IVUQOF02 ${ }^{4}$ ).

\section{Determination of the Critical Water Activity}

The critical water activity for an anhydrate and hydrate system is the water activity $\left(\mathrm{A}_{\mathrm{w}}\right)$ value, at a defined temperature and pressure, at which the anhydrous and hydrate forms are in equilibrium. The critical water activity for $\mathrm{AH}-\mathrm{B}$ versus the $\mathrm{MH}$ was established in the temperature range 4 to $40{ }^{\circ} \mathrm{C}$ using a solvent mediated slurry method. ${ }^{5-6}$

Solvent mixtures were prepared using propan-2-ol (anhydrous grade) and water. $\operatorname{ASPEN}^{7}$ (a process simulation software package) was used to calculate the water activity of water solvent mixtures through application of the non-random two-liquid model ${ }^{8}$ (NRTL). The water activity for the prepared solvents was confirmed using an Aqualab TDL $\left(25^{\circ} \mathrm{C}\right)$. This instrument measures the relative humidity $(\mathrm{RH})$ of a sample head space using a tuneable diode laser, calibrated against water activity standards. Solvent systems were initially saturated with AH$\mathrm{B}$, at or above the analysis temperature, and excess $\mathrm{AH}-\mathrm{B}$ and $\mathrm{MH}$ forms were added to the resultant solution $(1 \mathrm{~mL})$ to achieve an approximate $1: 1 \mathrm{w} / \mathrm{w}$ mixture of $\mathrm{AH}-\mathrm{B}$ and $\mathrm{MH}$ forms. These slurries were held at either 4,25 or $40{ }^{\circ} \mathrm{C}$ and the form present monitored, using powder X-ray diffraction, for a maximum of 8 weeks, or until a single form was present.

Slurry samples were analysed using a Bruker-AXS Ltd., D4 Endeavor powder X-ray diffractometer, fitted with a theta-theta goniometer, automatic beam divergence slit, automated sample changer and a Vantec detector. Slurry samples were prepared for analysis by mounting on a zero background, silicon wafer specimen mount and covered with an X-ray transparent (polyimide) film, added to retain the solvent environment and prevent phase transformation during the analysis. The samples were rotated whilst being irradiated with copper K-alpha Xrays (wavelength $=1.5406 \AA$ ) with the $\mathrm{X}$-ray tube operated at $35 \mathrm{kV} / 40 \mathrm{~mA}$. The analyses were performed with the goniometer running in continuous mode from $2-40^{\circ} 2 \theta$, step size $0.018^{\circ}$ 
20, step time 0.16 seconds. Data was collected using DIFRAC plus XRD Commander v2.6.0 and analysed using DIFFRAC.Suite EVA.v4.2. ${ }^{9}$ Solvent compositions, the measured water activity and the equilibrium solid form detected are detailed in Table S1.

At 25 and $40{ }^{\circ} \mathrm{C}$ all prepared mixtures converted to a single form. At $4{ }^{\circ} \mathrm{C}$ and $\mathrm{A}_{\mathrm{w}}=0.29$ both $\mathrm{AH}-\mathrm{B}$ and the MH persisted, there was no detectable change in the XRPD pattern peak heights for $\mathrm{AH}-\mathrm{B}$ or $\mathrm{MH}$ over an eight-week period. Therefore $\mathrm{A}_{\mathrm{w}}=0.29$ was taken to represent the critical water activity at $4{ }^{\circ} \mathrm{C}$. (Table S1, Figure S1). The critical water activity for AH-A versus $\mathrm{MH}$ at $25^{\circ} \mathrm{C}$ has previously been established to be in the range $\mathrm{A}_{\mathrm{w}}=0.20$ to 0.30 , this work being completed with a 2 hour period to avoid conversion to AH-B. ${ }^{1}$ At low water activity AH$\mathrm{C}$ was found to rapidly convert to $\mathrm{AH}-\mathrm{A}(<30 \mathrm{~min})$ and therefore it was not possible to determine the critical water activity between $\mathrm{AH}-\mathrm{C}$ and the $\mathrm{MH}$. Based on the relative stability of the polymorphic forms, AH-C as the least stable form crystallised, the critical water activity between $\mathrm{AH}-\mathrm{C}$ and $\mathrm{MH}$ can be assumed to be the same as, or lower than that measured for $\mathrm{AH}-$ A.

Table S1 Solid form identified from equilibrium slurries in IPA:water slurries at three different temperatures. The initial excess solids in the slurries had solid compositions of approximately 1:1 w/w AH$B$ and $M H$ and the initial saturation of the solution was achieved respect to AH-B.

\begin{tabular}{|c|c|c|c|c|c|c|c|}
\hline \multicolumn{3}{|c|}{ Water activity } & \multirow[t]{2}{*}{$\begin{array}{c}\text { Volume water } \\
(\mathrm{mL} / \mathrm{mL})\end{array}$} & \multirow[t]{2}{*}{$\begin{array}{c}\text { Volume IPA } \\
(\mathrm{mL} / \mathrm{mL})\end{array}$} & \multicolumn{3}{|c|}{ Identified solid form } \\
\hline $4^{\circ} \mathrm{C}$ & $25^{\circ} \mathrm{C}$ & $40^{\circ} \mathrm{C}$ & & & $4^{\circ} \mathrm{C}$ & $25^{\circ} \mathrm{C}$ & $40^{\circ} \mathrm{C}$ \\
\hline 0.00 & 0.00 & 0.00 & 0.0000 & 1.0000 & - & AH-B & - \\
\hline 0.10 & 0.10 & 0 & 0.0077 & 0.9923 & AH-B & AH-B & - \\
\hline 0.19 & 0.20 & 0.20 & 0.0164 & 0.9836 & AH-B & AH-B & AH-B \\
\hline 0.29 & 0.30 & 0.30 & 0.0266 & 0.9734 & MH/AH-B* & AH-B & AH-B \\
\hline 0.37 & 0.39 & 0.40 & 0.0387 & 0.9613 & MH & MH & AH-B \\
\hline \multirow[t]{6}{*}{0.47} & 0.49 & 0.50 & 0.0539 & 0.9461 & MH & $\mathrm{MH}$ & AH-B \\
\hline & 0.57 & 0.59 & 0.0745 & 0.9255 & - & $\mathrm{MH}$ & $\mathrm{MH}$ \\
\hline & 0.66 & 0.68 & 0.1043 & 0.8957 & - & MH & MH \\
\hline & 0.75 & & 0.1598 & 0.8402 & - & $\mathrm{MH}$ & - \\
\hline & 0.86 & & 0.4696 & 0.5304 & - & $\mathrm{MH}$ & - \\
\hline & 1.00 & & 1.0000 & 0.0000 & - & $\mathrm{MH}$ & - \\
\hline
\end{tabular}

- Condition not investigated. Values for water activity at $25{ }^{\circ} \mathrm{C}$ are measured values, 4 and $40{ }^{\circ} \mathrm{C}$ are calculated.

* Measured over an 8-week period with no change in form. 


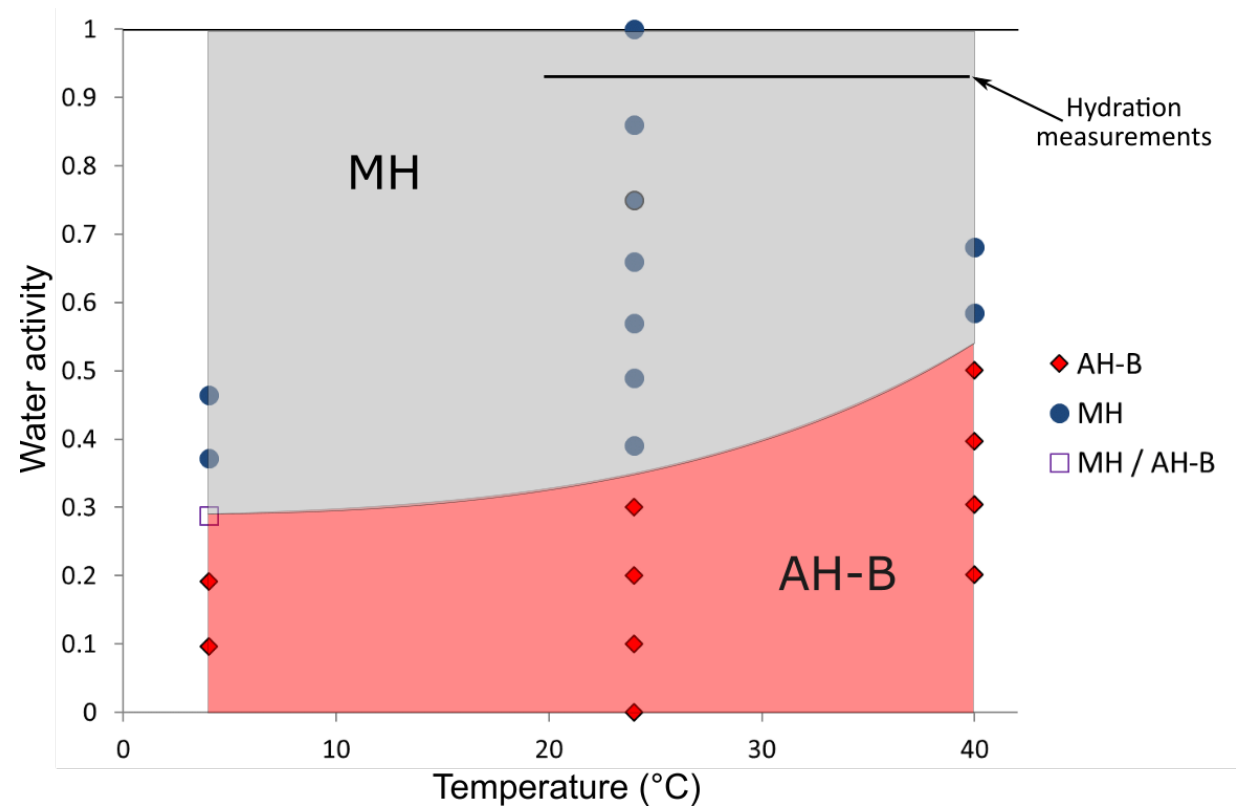

Figure S1 Thermodynamic stability of $\mathrm{AH}-\mathrm{B}$ and $\mathrm{MH}$ in the temperature range 4 to $40{ }^{\circ} \mathrm{C}$, including symbols donating experimental outcome.

\section{Hydration of Anhydrous Polymorphs}

The hydration behaviour of AH-A, AH-B and AH-C was measured at 20, 30, 35 and $40{ }^{\circ} \mathrm{C}$ using a Surface Measurement Systems Ltd DVS Adventure. Data collection was performed using DVS Adventure Control Software v0.106; ${ }^{10}$ analysis was performed using SMS DVS Standard Analysis v7.1.0.9, a Microsoft Excel Add-in. The method exposed the sample (25 $30 \mathrm{mg}$ ) to $0 \% \mathrm{RH}$ for a short period ( $2 \mathrm{hrs}$ ), sufficient to obtain an accurate dry weight, followed by a lengthy exposure at $92-93 \% \mathrm{RH}$, held at this humidity until equilibrium water sorption was achieved. A large humidity jump used can result in the equipment briefly exceeding the requested humidity, to avoid this, a step at $80 \% \mathrm{RH}$ ( 2 hours), was included prior to exposure to $92-93 \% \mathrm{RH}$. The hydration behaviour of each polymorph was monitored repeatedly over a 19-month period; during this time bulk samples were stored in capped glass vials at ambient conditions $\left(19-23{ }^{\circ} \mathrm{C}\right.$ and $\left.\leq 50 \% \mathrm{RH}\right)$. The humidity used in these hydration studies is significantly above the critical water activity $\left(A_{w}\right)$ for all the forms studied.

At the end of each DVS measurement the resultant solid form was confirmed using a Bruker AXS Ltd., D8 Endeavor, powder X-ray diffractometer, fitted with a theta-theta goniometer and a LynxEye XE-T detector. The primary motorized slits were set at a constant illumination of $11 \mathrm{~mm}$, and anti-scattering slit set at a constant distance of $2.2 \mathrm{~mm}$. Samples were prepared for analysis on a low background cavity, silicon wafer mount. The wafer mount was rotated at 15 
rpm, whilst being irradiated with copper K-alpha X-rays (wavelength $=1.5406 \AA$ ) with the Xray tube operated at $40 \mathrm{kV} / 40 \mathrm{~mA}$. The analyses were performed with the goniometer running in continuous mode from $2-55^{\circ} 2 \theta$, step size $0.019^{\circ} 2 \theta$, step time 0.10 seconds. Data was collected using DIFRAC Measurement Centre v7.3.19 and analysed using Bruker AXS DIFFRAC.Suite EVA.v5.0. ${ }^{9}$

The hydration of the anhydrous polymorphs is represented visually in Figure S2 and Figure S3. In Figure S2 the data is grouped by temperature and shows the differing kinetic stabilities of the three forms studied. AH-B was found to be the more kinetically stable and AH-C the least kinetically stable to hydration, this is in line with our previous studies conducted at 54 and 75 $\%$ RH. $^{1}$

Figure S3 demonstrates that the hydration rate of all the polymorphs is influenced by temperature, the rate increasing with an increase in temperature.
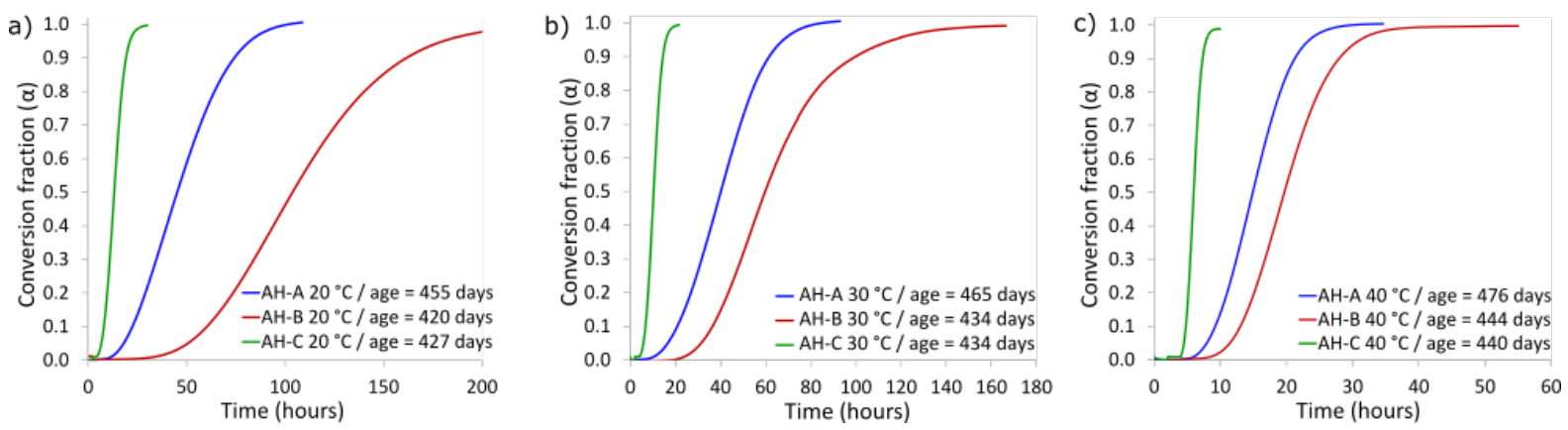

Figure S2 Effect of polymorphic form (AH-A, AH-B and AH-C) on the hydration rate at a) 20 , b) 30 and c) $40{ }^{\circ} \mathrm{C}$ (humidity maintained in the range $92-93 \% \mathrm{RH}$; sample age in the range 420 to 476 days.)
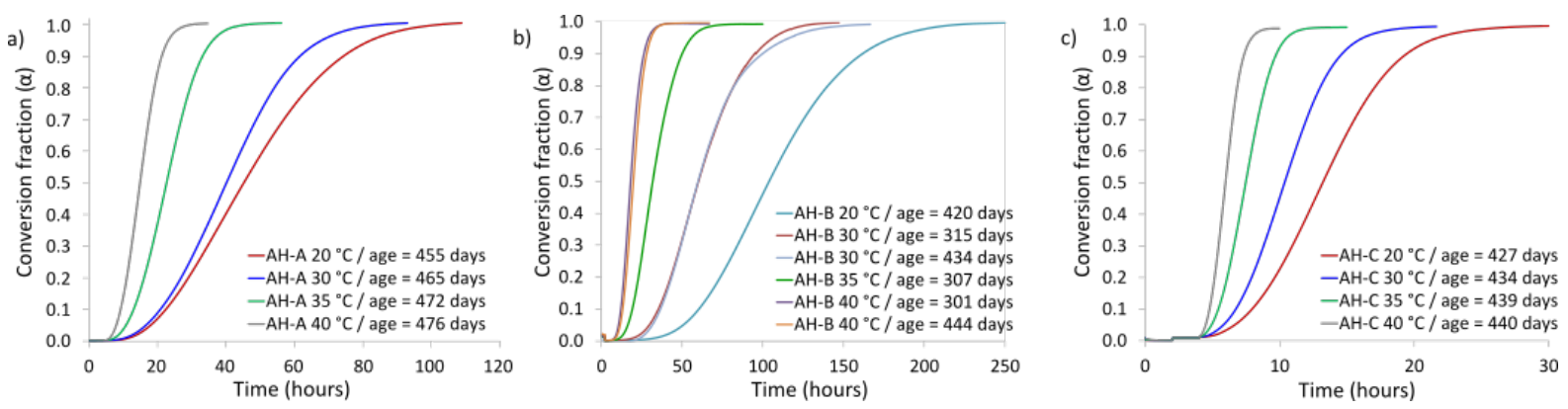

Figure S3 Effect of temperature on the hydration rate of a) AH-A, b) AH-B and c) AH-C (humidity maintained in the range $92-93 \% \mathrm{RH})$. 
Table S2 lists the hydration rate, at a conversion fraction of 0.5 , for the data sets collected, these are grouped by temperature and polymorphic form. The full data set is represented visually in Figure S4. For AH-A and AH-C the hydration rate increased with an increase in sample age, this effect was seen for all temperatures studied. Repeat measurements performed on samples within a similar age range show that this is a real effect and not related to variability in sampling. This aging behaviour was not apparent for AH-B. A representative data set of XRPD patterns, confirming that conversion has progressed from the anhydrous form to the monohydrate is presented: AH-A in Figure S5, AH-B in Figure S6 and AH-C in Figure S7.

Table S2 Effect of age on the hydration rate of AH-A, AH-B and AH-C at a conversion fraction ( $\alpha)$ of 0.5 . For repeat measurements taken at $30^{\circ} \mathrm{C}$.

\begin{tabular}{lcccccc}
\hline \multirow{2}{*}{$\begin{array}{l}\text { Temp. } \\
\left({ }^{\circ} \mathbf{C}\right)\end{array}$} & \multicolumn{2}{c}{ AH-A } & \multicolumn{2}{c}{ AH-B } & \multicolumn{2}{c}{ AH-C } \\
\cline { 2 - 7 } & age (days) & rate $(\boldsymbol{\alpha} / \mathbf{h r})$ & age (days) & rate $(\boldsymbol{\alpha} / \mathbf{h r})$ & age (days) & rate $(\boldsymbol{\alpha} / \mathbf{h r})$ \\
\hline 20 & 350 & 0.006 & 369 & 0.016 & 304 & 0.001 \\
20 & 455 & 0.018 & 420 & 0.010 & 427 & 0.090 \\
\hline 30 & 130 & 0.008 & 133 & 0.014 & 49 & 0.021 \\
30 & 210 & 0.019 & 315 & 0.017 & 279 & 0.069 \\
30 & 465 & 0.024 & 434 & 0.018 & 434 & 0.128 \\
30 & 553 & 0.047 & 558 & 0.014 & 563 & 0.332 \\
30 & 550 & 0.044 & & & 564 & 0.320 \\
30 & 558 & 0.044 & & & 565 & 0.300 \\
\hline 35 & 287 & 0.041 & 307 & 0.033 & 245 & 0.096 \\
35 & 472 & 0.050 & & & 439 & 0.236 \\
\hline 40 & 193 & 0.059 & 301 & 0.073 & 344 & 0.195 \\
40 & 348 & 0.079 & 444 & 0.070 & 440 & 0.398 \\
40 & 476 & 0.082 & & & & \\
\hline
\end{tabular}



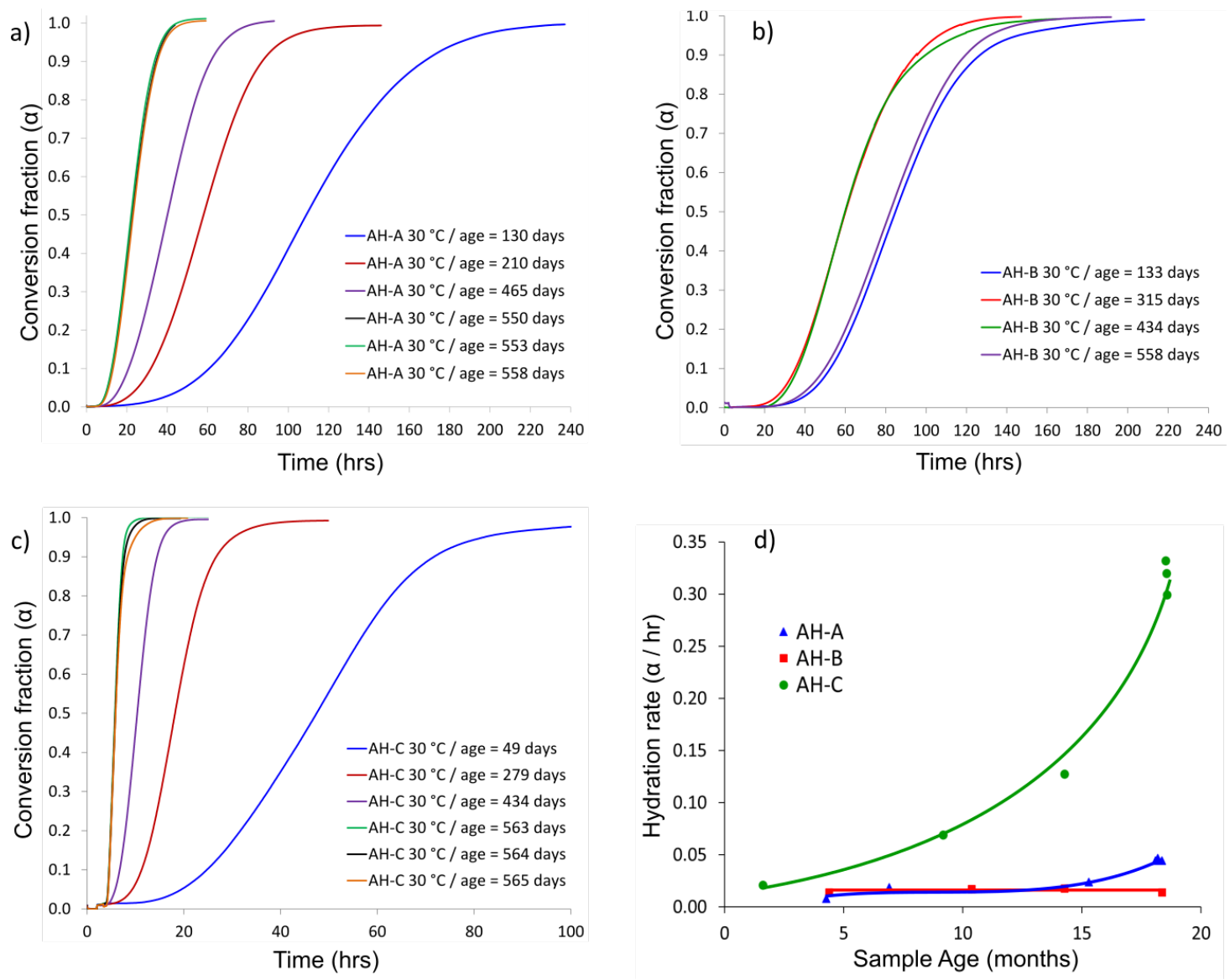

Figure S4 Effect of sample age on the hydration rate of a) AH-A, b) AH-B and c) AH-C (humidity maintained in the range $92-93 \% \mathrm{RH})$. Including data repeatability and d) conversion rate for AH-A and AH-C vs age.

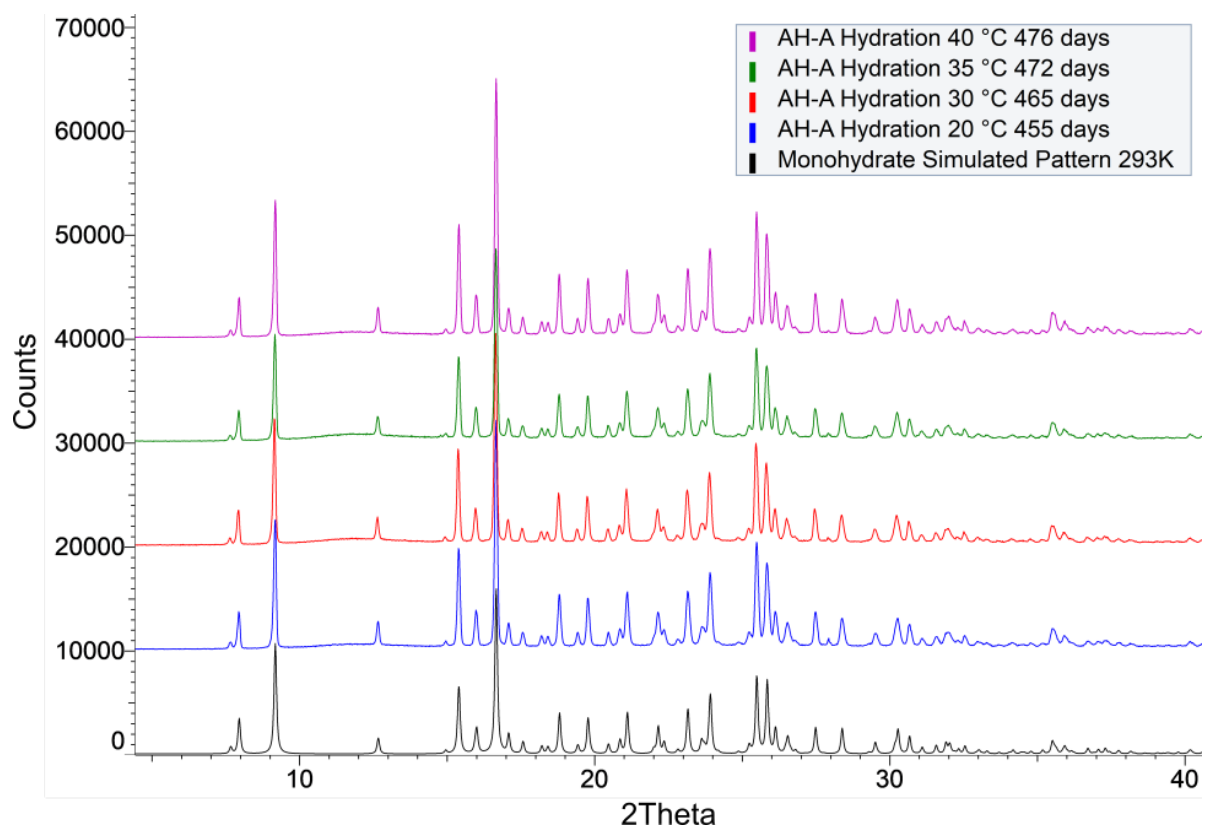

Figure S5 Powder X-ray diffraction patterns for AH-A following hydration at 92-93 \%RH and temperatures in the range $20-40{ }^{\circ} \mathrm{C}$. For comparison, the reference pattern of the monohydrate was simulated from the room temperature monohydrate structure (CSD refcode IVUQIZ) using mercury (black pattern). 


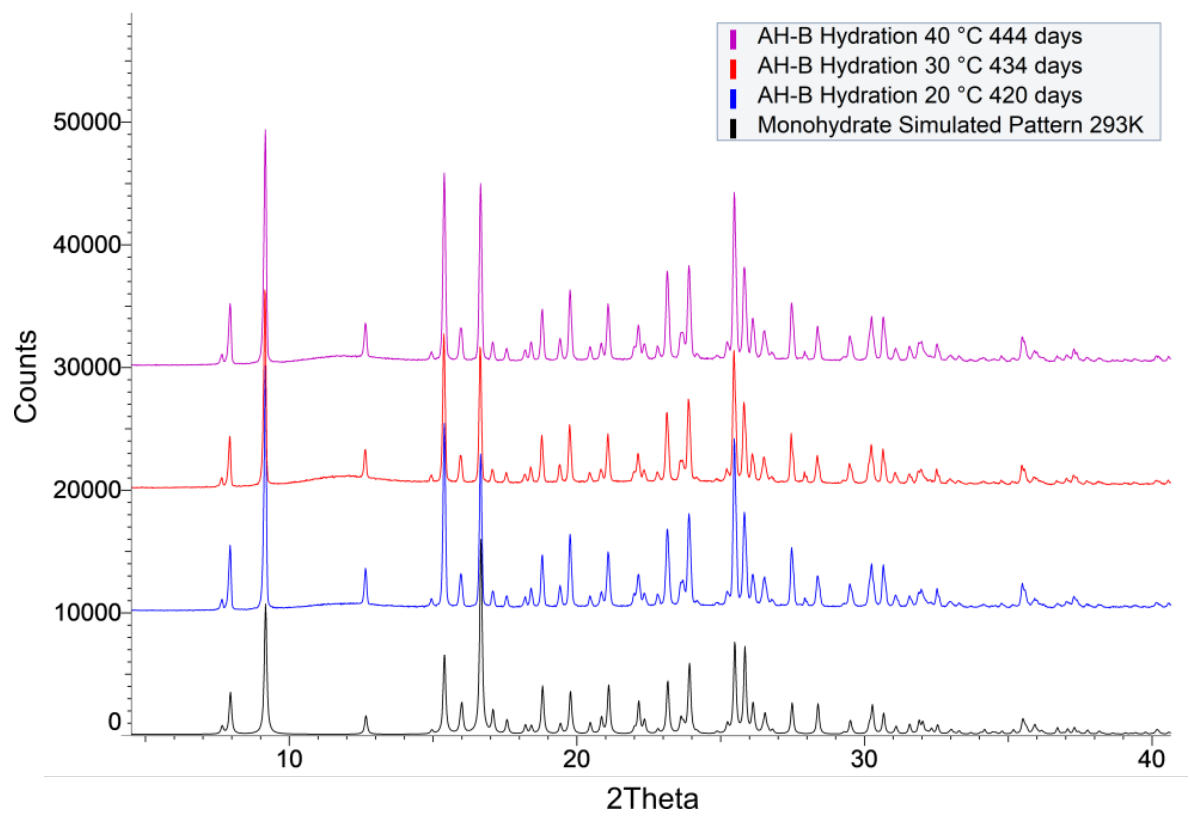

Figure S6 Powder X-ray diffraction patterns for AH-B following hydration at 92-93 \%RH and temperatures in the range $20-40{ }^{\circ} \mathrm{C}$. For comparison, the reference pattern of the monohydrate was simulated from the room temperature monohydrate structure (CSD refcode IVUQIZ) using mercury (black pattern).

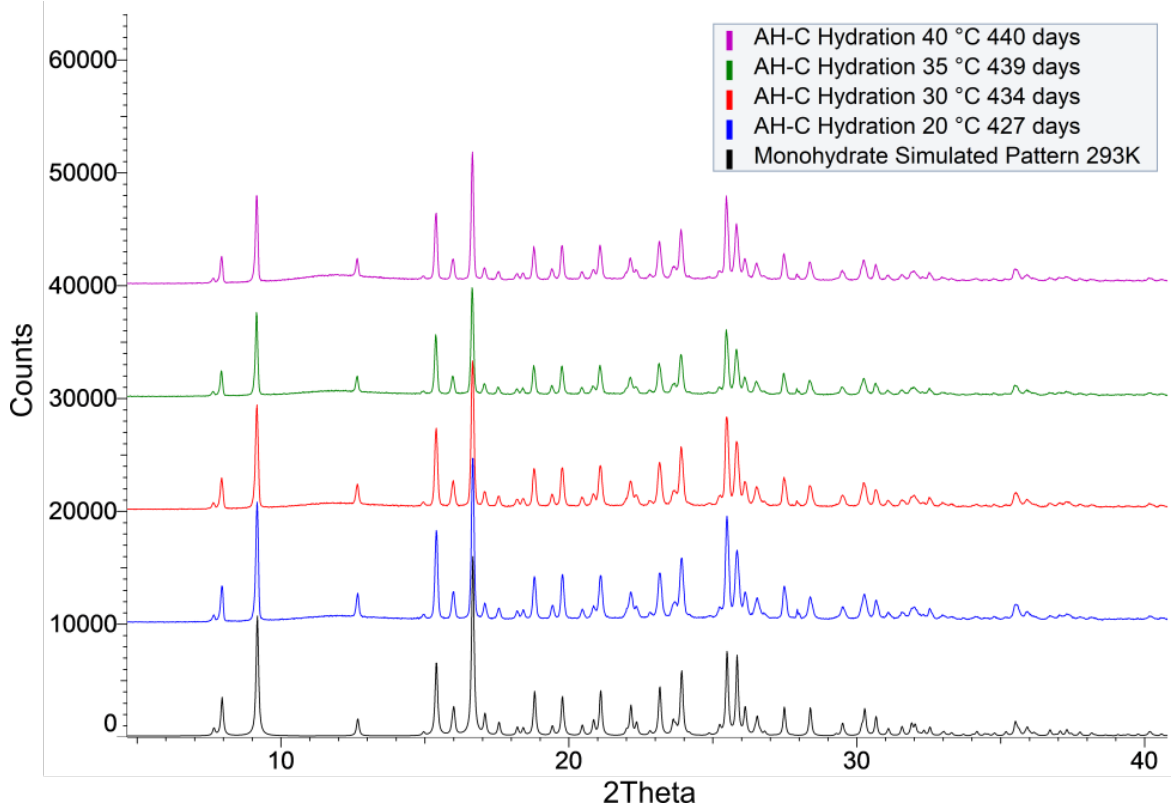

Figure S7 Powder X-ray diffraction patterns for AH-C following hydration at 92-93 \%RH and temperatures in the range $20-40{ }^{\circ} \mathrm{C}$. For comparison, the reference pattern of the monohydrate was simulated from the room temperature monohydrate structure (CSD refcode IVUQIZ) using mercury (black pattern). 


\section{Powder X-ray Diffraction of Aged Samples}

\subsection{High Resolution Synchrotron X-ray Powder Diffraction (HR- SXRPD)}

Aged samples, alongside samples spiked with $0.5 \% \mathrm{w} / \mathrm{w} \mathrm{MH}$, were measured using beamline I1 $1^{11}$ at Diamond Light Source (DLS). Samples were prepared by filling $0.7 \mathrm{~mm}$ diameter borosilicate capillaries; these were sealed with bee's wax. Samples containing $0.5 \% \mathrm{w} / \mathrm{w}$ of monohydrate were prepared. Approximately $150 \mathrm{mg}$ of each anhydrous polymorph was accurately weighed into a pressed aluminium foil weighing boat, this was transferred into the base of a $15 \mathrm{~mL}$ glass vial. Approximately $1.3 \mathrm{mg}$ of $\mathrm{MH}$ was accurately weighed into a pressed aluminium foil weighing boat, with a known weight transferred to the surface of each preweighed anhydrous form. The quantity of additional anhydrous polymorph required to achieve $0.5 \% \mathrm{w} / \mathrm{w} \mathrm{MH}$ was calculated relative to the pre-weighed $\mathrm{MH}$ and added to the vial. The vial was gently rolled to mix the content. This was followed by multiple short ( 5 x 3 second) periods of vortex mixing, tapping and rolling the vial between each.

I11 is designed to deliver monochromatic X-rays in the energy range of 5-30 keV (0.4-2.5 $\AA$ ) and is equipped with a fixed-exit double-bounce monochromator; this experiment was conducted using a pair of Si (111) crystals. The beam at the sample position was unfocused, with a beam size of $2.5 \mathrm{~mm} \times 0.5 \mathrm{~mm}(\mathrm{~h} \times \mathrm{v})$. The beamline energy was calibrated using a silicon powder standard giving a wavelength $(\lambda)$ of $0.825056 \AA$ (zero point $0.000833^{\circ}$ ). During the measurements, conducted at room temperature, each capillary was continuously spun. The data was collected using the multi-analyser crystal (MAC) detector system over a 2-theta range of $0-150^{\circ}$ using constant velocity scan. For the final data sets the raw data was rebinned to 3 mdeg steps.

\subsection{X-ray Powder Diffraction (XRPD)}

The effectiveness of the MH spiking and mixing method was assessed prior HR-SXRPD analysis by filling all the prepared AH-A-MH blend into 5 individual capillaries. In addition, stored samples were retested at an age of $\sim 30$ months. 
Capillaries were analysed using a Bruker-AXS Ltd., D8 Advance, powder X-ray diffractometer, fitted with a theta-theta goniometer, automatic beam divergence slit and a LynxEye detector. Samples were prepared for analysis by filling a $0.7 \mathrm{~mm}$ diameter borosilicate capillary. The specimen was rotated whilst being irradiated with copper K-alpha $\mathrm{X}$-rays (wavelength $=1.5406 \AA$ ) with the $\mathrm{X}$-ray tube operated at $40 \mathrm{kV} / 40 \mathrm{~mA}$. The analyses were performed with the goniometer running in continuous mode from $2-55^{\circ} 2 \theta$, step size $0.011^{\circ} 2 \theta$, step time 12 seconds. Data was collected using DIFRAC plus XRD Commander v2.6.1 and analysed using Bruker AXS DIFFRAC.Suite EVA.v4.2.1.10. ${ }^{9}$ An estimate on the mixing efficiency was made based on both peak height and area for the $16.6^{\circ} 2$-theta peak in relation to the sum of the net peak area or height for each of the 5 measurements.

The mixing efficiency for the method used to spike the anhydrous samples with monohydrate is shown for $\mathrm{AH}-\mathrm{A}$ in Figure S8, the $\mathrm{MH}$ peaks at 9.2 and $16.6^{\circ} 2$-theta are visible in each replicate, the samples prepared are estimated to be in the range 0.3 to $0.6 \% \mathrm{w} / \mathrm{w} \mathrm{MH}$.

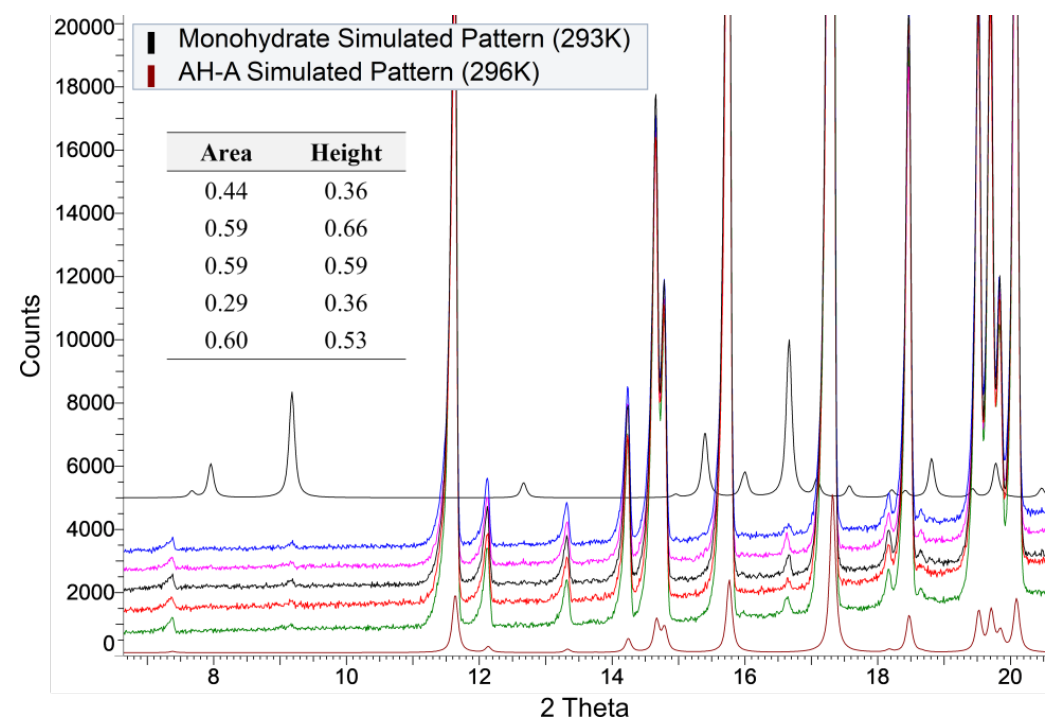

Figure S8 Powder XRPD patterns for 5 cappilaries demonstrating mixing efficiency for AH-A spiked with $0.5 \% \mathrm{w} / \mathrm{w}$ monohydrate. Composition (\% MH) shown calculated in relation to the net peak area and height of the $\mathrm{MH}$ peak at $16.6^{\circ}$ 2-theta.

HR-SXRPD data for AH-A, AH-B and AH-C compared to MH spiked samples and the MH is shown in Figure S9. In each MH spiked sample, the $\mathrm{MH}$ is detected at $\sim 0.5 \% \mathrm{w} / \mathrm{w}$, however monohydrate was not detected in the anhydrous samples. For AH-A and AH-B the base line noise would obscure $\sim 0.05 \% \mathrm{MH}$, for $\mathrm{AH} \mathrm{C} \sim 0.14 \% \mathrm{MH}$. Peaks representative of the $\mathrm{MH}$ form at 9.2 and $16.6^{\circ} 2$-theta in the laboratory data are equivalent to the peaks at 4.9 and $8.9^{\circ}$ 2-theta in the Hi-Res synchrotron data. 

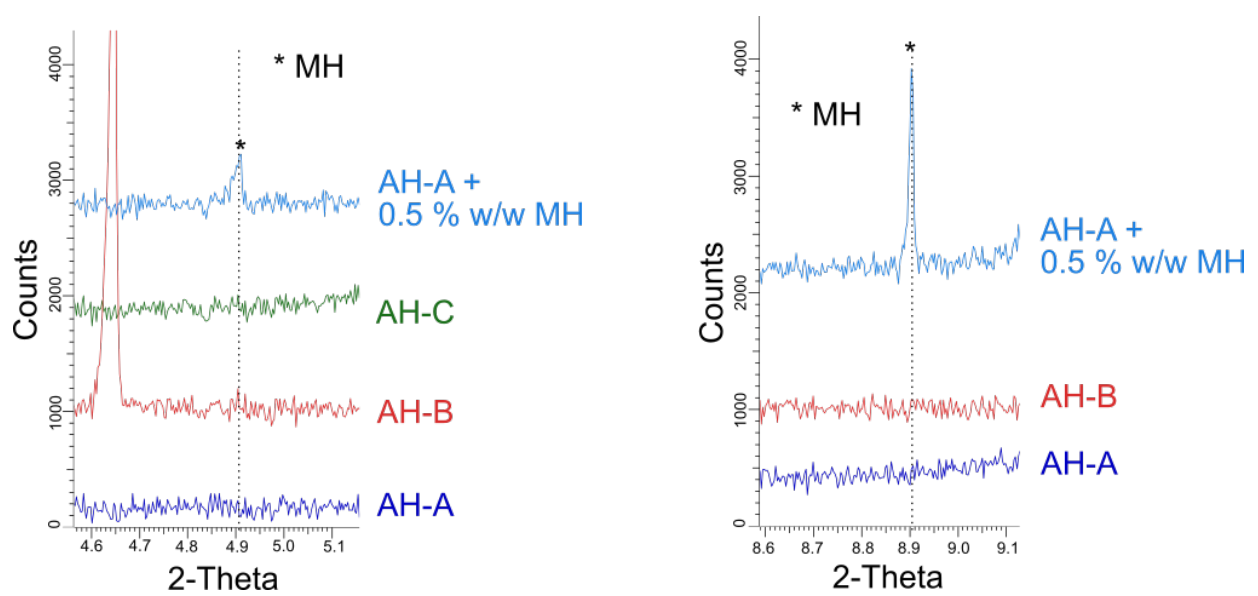

Figure S9 HR-SXRPD data sets for AH-A, AH-B and AH-C samples aged for 17 months, overlaid with prepared AH-A sample spiked with MH $(0.5 \% \mathrm{w} / \mathrm{w})$. The 2-theta ranges specific to the identification of the MH are shown.

\section{Confocal Raman Microscopy (CRM)}

Samples of aged AH-A (22 months) were mounted onto a $10 \mathrm{~mm}$ mica disc coated with a thin layer of Araldite ${ }^{\circledR}$, which was left to partially dry before positioning the AH-A crystals. The surface $(\sim 1 \mu \mathrm{m})$ of the crystals was then analysed using CRM and, to demonstrate reproducibility, duplicate measurements were collected from three crystals. Samples of MH and AH-A (freshly crystallised batch) were prepared by transferring material onto a clean glass microscope slide and lightly pressing to form a flat powder bed. Raman reference spectra were then collected for comparison with the data from aged samples.

Raman spectra were collected using an Alpha500R confocal Raman microscope (WITec, $\mathrm{GmbH}$ ) equipped with an XTRA II $785 \mathrm{~nm}$ diode laser (Toptica Photonics) and controlled using WITec Control FIVE software. Prior to use, the spectrometer was calibrated using an Ar:Hg emission lamp. The laser source was focused onto the sample using a 100x/0.9N.A. objective (Zeiss EC Epiplan-Neofluar) and back-scattered photons were collected using the same objective. The intensity of the elastic (Rayleigh) scattered light was suppressed by a filter, whilst the Raman signal from the inelastically scattered Stokes' light was passed through a 50 $\mu \mathrm{m}$ multimode fibre optic, before being dispersed by a 600 lines $/ \mathrm{mm}$ diffraction grating onto a Newton 940 Charge-coupled Device (CCD) detector (Andor, UK) held at $-65^{\circ} \mathrm{C}$. This experimental setup provided a spectral resolution of approximately $4 \mathrm{~cm}^{-1}$ and a spatial resolution of $<1 \mu \mathrm{m}$. Spectra are comprised from a minimum of 300 co-added scans with an acquisition time of 0.1 seconds. Data were processed using WITec Project FIVE software. 
Data are presented in Figure S10. Characteristic peaks, that can be used to distinguish between the $\mathrm{MH}$ and $\mathrm{AH}-\mathrm{A}$, are highlighted in the figure, and corresponding peak lists are provided in Table S3.

The confocal set up of the Raman microscope delivers diffraction limited spatial resolution resulting in a sampling volume of approximately $1 \mu \mathrm{m}^{3}$. Based on the level of spectroscopic distinction between the polymorphic forms it is reasonable to estimate a detection limit within the sampling volume of $10 \%$ for the monohydrate. The estimated limit of detection is essentially independent of the distribution of the monohydrate within the sampling volume, therefore, the technique is equally sensitive to a $100 \mathrm{~nm}$ surface coverage, as to a $10 \%$ homogenous distribution. The spectra collected from AH-A, aged for 22 months, is entirely consistent with AH-A, with no evidence for the presence of $\mathrm{MH}$.

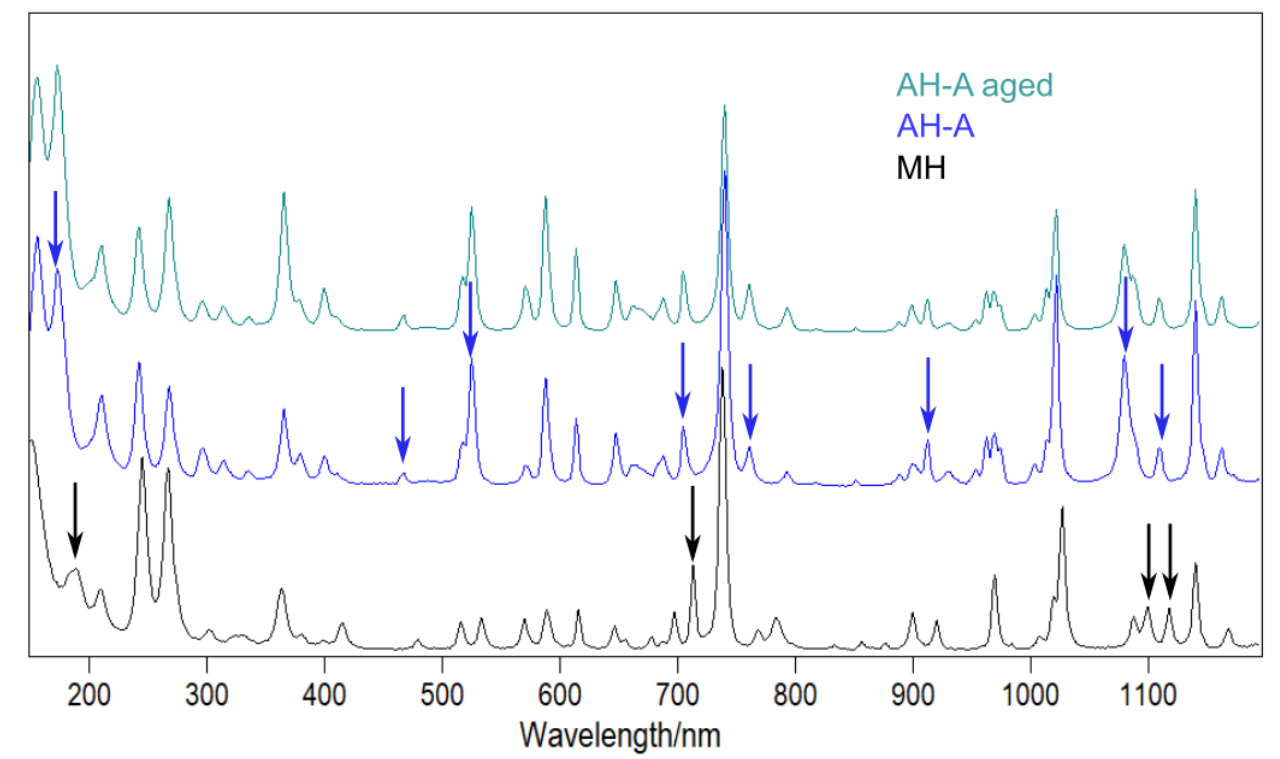

Figure S10 Raman spectra of MH, AH-A and AH-A-aged. With characteristic peaks for MH and AH-A marked (arrows)

Table S3 Raman peak lists for MH and AH-A.

\begin{tabular}{|c|c|c|}
\hline \multicolumn{3}{|c|}{ Raman shift $/ \mathrm{cm}^{-1}$} \\
\hline MH & AH-A & AH-A 22months \\
\hline & 174 & 174 \\
\hline \multirow[t]{3}{*}{190} & 467 & 466 \\
\hline & 526 & 526 \\
\hline & 705 & 705 \\
\hline \multicolumn{3}{|l|}{714} \\
\hline & 761 & 761 \\
\hline & 913 & 912 \\
\hline & 1080 & 1080 \\
\hline \multicolumn{3}{|l|}{1100} \\
\hline & 1110 & 1109 \\
\hline 1117 & & \\
\hline
\end{tabular}




\section{ATR-FTIR}

Attenuated total reflectance Fourier-transform infrared (ATR-FTIR) spectra were collected using a Nicolet iS50 FTIR spectrometer (Thermo Scientific) equipped with a diamond ATR accessory. Aged samples ( 30 months) of AH-A, AH-B and AH-C were analysed and compared to a reference spectrum of the $\mathrm{MH}$. All spectra were collected at $4 \mathrm{~cm}^{-1}$ and comprised 32 co-added scans. The spectra are presented in Figure S11 and Figure S12. There is no evidence for the presence of $\mathrm{MH}$ in the aged AH-B or AH-C samples. The intensity observed in the $\mathrm{O}-\mathrm{H}$ stretch region $\left(3500-3100 \mathrm{~cm}^{-1}\right)$ of the aged $\mathrm{AH}-\mathrm{A}$ spectrum could indicate the presence of $\mathrm{MH}$. However, if this band was exclusively due to the $\mathrm{MH}$, based on its intensity one would reasonably expect to be able to identify features within the fingerprint region (Figure S12) of the aged AH-A spectrum that could be attributed to the $\mathrm{MH}$. For example, the appearance of a new peak at $834 \mathrm{~cm}^{-1}$, a shoulder appearing alongside the peak at $760 \mathrm{~cm}^{-1}$ and an increase in the baseline at $\sim 800 \mathrm{~cm}^{-1}$. Since none of these are observed it seems unlikely that the intensity in the $\mathrm{O}-\mathrm{H}$ stretch region is due to $\mathrm{MH}$.

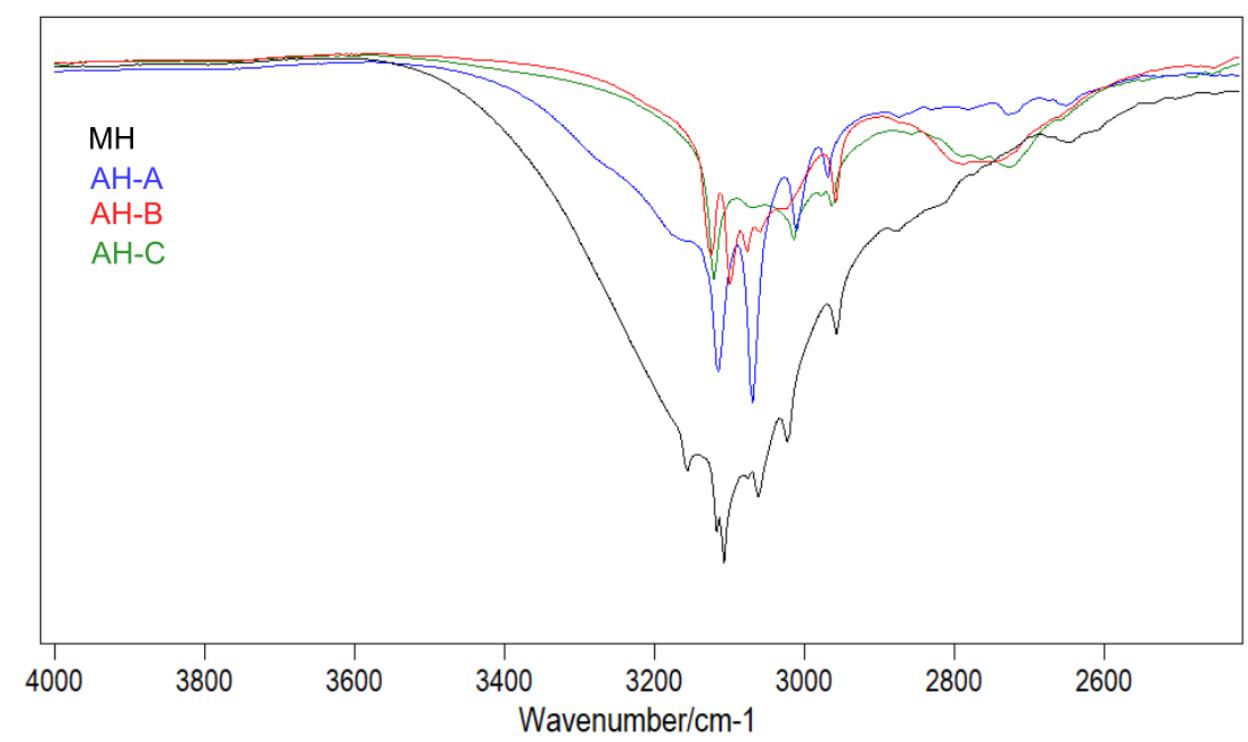

Figure S11 ATR-FTIR spectra of AH-A, AH-B, and AH-C aged for $\sim 30$ months, and $\mathrm{MH}$. O-H stretch region. 


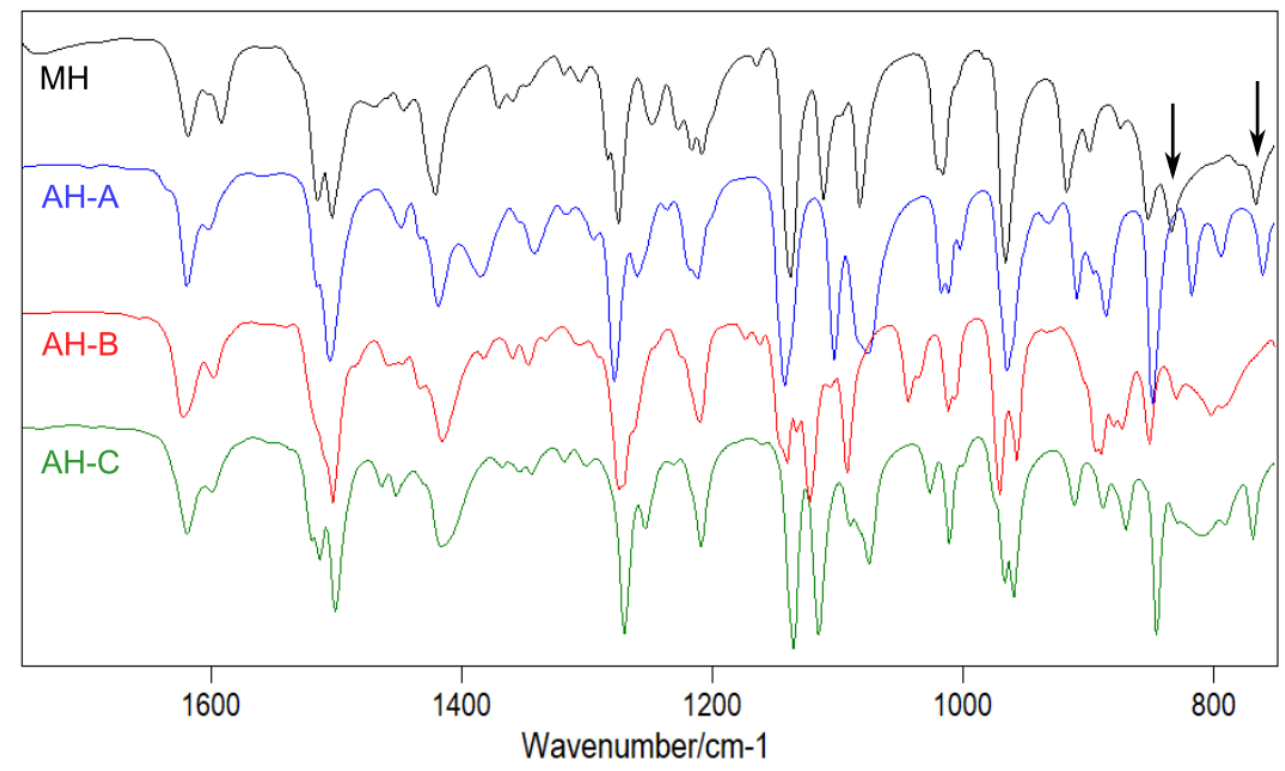

Figure S12 ATR-FTIR spectra of AH-A, AH-B, and AH-C aged for $\sim 30$ months, and MH. With characteristic peaks for MH marked (arrows). Fingerprint region.

\section{Activation Energy}

The rate of a process (in this case hydration) can be described using three variables, temperature $(\mathrm{T})$ the extent of the conversion $(\alpha)$ and the pressure $(\mathrm{P}) .{ }^{12}$ The pressure dependence, $h(P)$ can be ignored, since all our studies are performed at constant pressure (atmospheric and water partial pressure). The dependence of a process on temperature is represented by the rate constant $\mathrm{k}(\mathrm{T})$, and the dependence on the extent of conversion $(\alpha)$ (range 0 to 1 ) is represented by a kinetic reaction model $(f(\alpha))$, equation 1 . In our case $\alpha$ is determined experimentally by the total fraction of mass gained, with $\alpha=1$ representing the gain of 1 mole equivalent of water. The reaction model $f(\alpha)$ is a hypothetical representation of the reaction mechanism. Nucleation, growth from nuclei, movement of a phase boundary through the crystal and diffusion (in this case water) will all impact the reaction mechanism.

The Arrhenius equation (2) is used to describe the temperature dependence of reaction rates. A is the pre-exponential factor, $E_{a}$ the activation energy and $\mathrm{R}$ the Gas Constant (8.314 $\mathrm{J} \mathrm{K}^{-1} \mathrm{~mol}^{-1}$ ). The pre-exponential factor does not vary significantly with temperature and therefore within a small temperature range, can be assumed to be a constant. The rate of a process is influenced by variables such as sample volume, number of nuclei, specific surface area, particle geometry and partial pressure. ${ }^{13}$ 


$$
\begin{gathered}
\frac{d \alpha}{d t}=k(T) f(\alpha) h(P) \\
k(T)=A e^{\left(\frac{-E \alpha}{R T}\right)}
\end{gathered}
$$

Activation energies $\left(E_{a}\right)$, for hydration of the anhydrous polymorphs, were calculated using a "model-free" isoconversional approach. ${ }^{12}$ This is based on the principal that the reaction rate, at a defined conversion fraction $(\alpha)$, is only a function of the temperature (at constant pressure). The activation energy is calculated using the rates, at defined $\alpha$, from a series of measurements conducted at differing temperature $\left(E_{\alpha}\right)$. Therefore, the dependence of $E_{a}$ on $\alpha$ is established with significant variation in $\mathrm{E}_{\alpha}$ indicating that a kinetically complex process is in play, such that a single model would not be applicable throughout the conversion.

Taking the logarithmic derivative of the reaction rate (equation 1), for a reaction at a constant pressure, gives equation 3. At any given constant value of $\alpha$, then $f(\alpha)$ is also a constant, therefore the final term in equation 3 equates to zero. Combining equations 2 and 3 provides equation 4.

$$
\left[\left(\frac{d \ln (d \alpha / d t)}{d T^{-1}}\right)\right]_{\alpha}=\left[\left(\frac{d \ln k(T)}{d T^{-1}}\right)\right]_{\alpha}+\left[\left(\frac{d \ln f(\alpha)}{d T^{-1}}\right)\right]_{\alpha}
$$

The isoconversional method applied here can be applied to any temperature program based on equation 4. Hydration rates (across a conversion fraction range of $0.1-0.9$ ) were calculated at 0.1 intervals from linear regression analysis of portions of the data set. An example of the regression analysis performed on the data is provided in Figure S13. The conversion fraction was calculated by dividing the weight gain (relative to the dry weight) by the expected weight gain for 1 mole of water $(5.88 \% \mathrm{w} / \mathrm{w}$; fluconazole MW 306.27).

The rate data was compiled into an Arrhenius plot, the slope of the data at each conversion fraction was calculated using regression analysis. The derived rate data was used to calculate the activation energy values for each conversion fraction (equation 4).

$$
\frac{d \ln (d \alpha / d t)}{d T^{-1}}=-\frac{E_{\alpha}}{R}
$$


Ideally multiple measurements would be performed, however the aging effect noted for AH-A and $\mathrm{AH}-\mathrm{C}$ prevented this. As aging did not impact $\mathrm{AH}-\mathrm{B}$, all data sets collected for $\mathrm{AH}-\mathrm{B}$ were applied to the activation energy calculation. The pre-exponential factor (A), found in the Arrhenius equation, varies only slightly with temperature and is approximately constant for small temperature changes. At lower temperatures, as applied here, the temperature range needs to be particularly tight, so $E_{a}$ calculations were performed on data sets collected at 30,35 and $40{ }^{\circ} \mathrm{C}$.

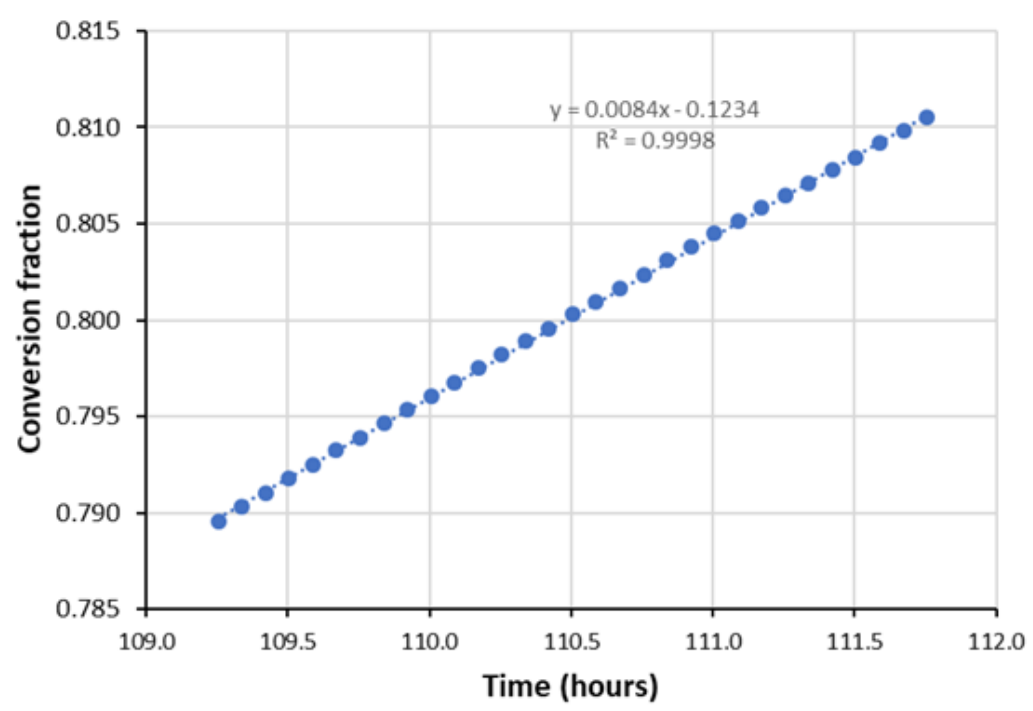

Figure S13 Example of the regression analysis performed, on DVS data, to extract hydration rate values at each conversion fraction.

The rates used in the calculation of activation energies are listed in Table S4 and Table S5.

Table S4 Conversion rate values $(\alpha / \mathrm{hr})$ used in the calculation of the activation energy for hydration of $\mathrm{AH}-$ $A$ and AH-C.

\begin{tabular}{|c|c|c|c|c|c|c|c|c|}
\hline \multirow{4}{*}{$\begin{array}{l}\text { Conversion } \\
\text { fraction }\end{array}$} & \multicolumn{8}{|c|}{ Temperature $\left({ }^{\circ} \mathrm{C}\right)$ and age (days) } \\
\hline & \multicolumn{5}{|c|}{ AH-A } & \multicolumn{3}{|c|}{ AH-C } \\
\hline & 30 & 40 & 30 & 35 & 40 & 30 & 35 & 40 \\
\hline & 210 & 193 & 465 & 472 & 476 & 434 & 439 & 440 \\
\hline 0.1 & 0.009 & 0.030 & 0.014 & 0.027 & 0.046 & 0.068 & 0.120 & 0.213 \\
\hline 0.2 & 0.014 & 0.045 & 0.019 & 0.038 & 0.065 & 0.100 & 0.182 & 0.310 \\
\hline 0.3 & 0.017 & 0.054 & 0.022 & 0.045 & 0.077 & 0.120 & 0.214 & 0.367 \\
\hline 0.4 & 0.018 & 0.059 & 0.024 & 0.049 & 0.082 & 0.127 & 0.230 & 0.393 \\
\hline 0.5 & 0.019 & 0.059 & 0.024 & 0.050 & 0.082 & 0.128 & 0.236 & 0.398 \\
\hline 0.6 & 0.018 & 0.058 & 0.023 & 0.047 & 0.078 & 0.121 & 0.230 & 0.378 \\
\hline 0.7 & 0.016 & 0.052 & 0.021 & 0.042 & 0.069 & 0.108 & 0.201 & 0.340 \\
\hline 0.8 & 0.012 & 0.041 & 0.017 & 0.034 & 0.056 & 0.080 & 0.165 & 0.266 \\
\hline 0.9 & 0.007 & 0.026 & 0.010 & 0.021 & 0.035 & 0.042 & 0.099 & 0.150 \\
\hline
\end{tabular}


Table S5 Conversion rate values $(\alpha / \mathrm{hr})$ used in the calculation of the activation energy for hydration of $\mathrm{AH}-$ B.

\begin{tabular}{cccccccc}
\hline \multirow{2}{*}{$\begin{array}{c}\text { Conversion } \\
\text { fraction }\end{array}$} & \multicolumn{7}{c}{ Temperature $\left({ }^{\circ} \mathbf{C}\right)$ and age (days) } \\
\cline { 2 - 8 } & $\mathbf{3 0}$ & $\mathbf{3 0}$ & $\mathbf{3 0}$ & $\mathbf{3 0}$ & $\mathbf{3 5}$ & $\mathbf{4 0}$ & $\mathbf{4 0}$ \\
\hline 0.1 & 0.008 & 0.011 & 0.011 & 0.008 & 0.022 & 0.043 & 0.039 \\
0.2 & 0.012 & 0.015 & 0.016 & 0.012 & 0.031 & 0.064 & 0.056 \\
0.3 & 0.014 & 0.018 & 0.018 & 0.014 & 0.035 & 0.073 & 0.065 \\
0.4 & 0.014 & 0.018 & 0.019 & 0.014 & 0.035 & 0.076 & 0.070 \\
0.5 & 0.014 & 0.017 & 0.018 & 0.014 & 0.033 & 0.073 & 0.070 \\
0.6 & 0.013 & 0.016 & 0.016 & 0.014 & 0.029 & 0.067 & 0.065 \\
0.7 & 0.011 & 0.013 & 0.013 & 0.012 & 0.024 & 0.056 & 0.055 \\
0.8 & 0.008 & 0.010 & 0.009 & 0.010 & 0.019 & 0.042 & 0.042 \\
0.9 & 0.004 & 0.006 & 0.004 & 0.006 & 0.011 & 0.023 & 0.024 \\
\hline
\end{tabular}

Calculated activation energy values for individual conversion fractions $(\alpha)$ are listed in Table S6 along with the average of the data for conversion fractions in the range $0.1-0.7$. Values are represented visually in Figure S14.

Table S6 Activation energy values $(\mathrm{kJ} / \mathrm{mol})$ for the conversion fraction rage for hydration of fluconazole polymorphs

\begin{tabular}{|ccc|c|c|}
\hline \multirow{2}{*}{$\begin{array}{c}\text { Conversion } \\
\text { fraction }\end{array}$} & AH-A & AH-B & AH-C \\
\cline { 2 - 5 } & $\sim \mathbf{2 0 0}$ & $\sim \mathbf{4 6 0}$ & all & 435 \\
\hline 0.1 & 92.0 & 94.3 & 117.2 & 90.8 \\
0.2 & 92.3 & 95.8 & 117.5 & 89.4 \\
0.3 & 91.9 & 98.2 & 117.2 & 89.8 \\
0.4 & 91.8 & 97.6 & 117.9 & 90.4 \\
0.5 & 91.8 & 97.2 & 118.5 & 90.3 \\
0.6 & 94.0 & 96.3 & 119.1 & 91.0 \\
0.8 & 95.1 & 94.6 & 118.7 & 95.3 \\
0.9 & 96.2 & 94.0 & 119.6 & 101.8 \\
\hline Average $\alpha=0.1-0.7$ & 99.7 & 97.0 & 123.4 & $90.0(0.7)$ \\
\hline
\end{tabular}

Average activation energy values were calculated from activation energy values obtained in the conversion fraction range 0.1 to 0.7 . Standard deviations are shown in parenthesis. 


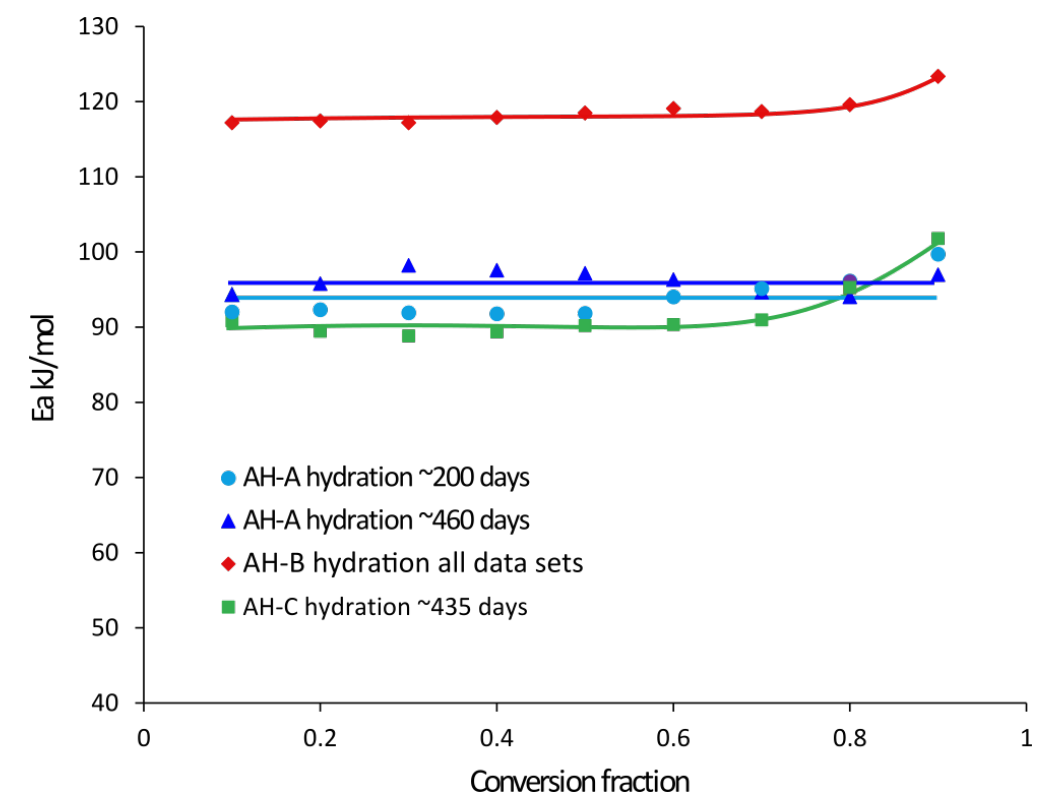

Figure S14 Dependence of activation energy on conversion fraction for the hydration of AH-A, AH-B and AH-C polymorphs of fluconazole.

\section{Calculation of Lattice Energies}

Experimental crystal structures for AH-A, AH-B and AH-C (IVUQOF, IVUQOF01 and IVUQOF-02 respectively) were retrieved from the CSD. Geometry optimisation was performed using the VASP (Vienna Ab initio Simulation Package) computer program using the DFT-d2 method of Grimme. ${ }^{14}$ A convergence criteria of $0.005 \mathrm{eV} / \AA$ and a kinetic energy cut off of $520 \mathrm{eV}$ were applied. Geometry optimisation was performed in two steps, first optimising cell-shape and volume plus atomic positions, and second keeping the cell constant and allowing only atomic positions to optimise. The Monkhorst-Pack k-point mesh used for each polymorph is listed in Table S7. The output geometry optimised structure was compared to the original experimental structure using the COMPACK algorithm (as implemented in Materials Mercury), the $\mathrm{RMS}_{20}$ values are listed in Table S8.

Table S7 Monkhorst-Pack k-point mesh values used for geometry optimisation.

\begin{tabular}{llll}
\hline SCD Refcode & a & b & c \\
\hline IVUQOF & 4 & 4 & 2 \\
IVUQOF01 & 4 & 1 & 2 \\
IVUQOF02 & 2 & 5 & 1 \\
\hline
\end{tabular}


Table S8 Packing similarity, comparison of experimental and computational structures (20 molecules)

\begin{tabular}{lc}
\hline Form & RMS $_{\mathbf{2 0}}$ \\
\hline AH-A (IVUQOF) & 0.314 \\
AH-B (IVUQOF01) & 0.210 \\
AH-C (IVUQOF02) & 0.159 \\
\hline
\end{tabular}

A third set of optimisations were performed using a super cell with periodic cell axis lengths of 40x40x40 ̊ with only one single molecule in it. In this optimisation, unit cell parameters are kept fixed whilst atomic coordinates are optimised. This is to estimate the energy of the molecular conformation in the gas-phase. The three conformations in IVUQOF, IVUQOF01 and IVUQOF02 were all optimised in this way and the lowest energy conformation was then taken as reference.

The lattice energies (Table S9), for each anhydrous form, were then calculated by subtracting the electronic energy of the most stable conformation in the gas-phase from the electronic energy of the molecule in the crystal.

Table S9 Calculated lattice energy values (kJ/mol) for fluconazole AH-A, AH-B and AH-C.

\begin{tabular}{lccc}
\hline Form & Refcode & $\begin{array}{c}\mathbf{E}_{\text {latt }} \\
(\mathbf{k J} / \mathbf{m o l})\end{array}$ & $\begin{array}{c}\mathbf{E}_{\text {latt vs AH-C }} \\
(\mathbf{k J} / \mathbf{m o l})\end{array}$ \\
\hline AH-A & IVUQOF & -172.4 & -1.7 \\
AH-B & IVUQOF01 & -174.2 & -3.5 \\
AH-C & IVUQOF02 & -170.7 & 0.0 \\
\hline
\end{tabular}

\section{Solution Calorimetry}

Measurements were performed at $25{ }^{\circ} \mathrm{C}$ using a Thermometric 2225 Precision Solution Calorimeter (Thermometric now TA Instruments) fitted with a 2280 TAM Interface Accessory. Data collection was performed using 2225 Solution Calorimetry Software v1.2.

The samples (100 mg) were sealed (rubber stopper plus beeswax) into a $1.1 \mathrm{~mL}$ glass crushing ampoule. Ampoules were carefully selected such that the glass was extremely thin at the ampoule breakage points, this ensuring a clean break. Ethanol, (absolute), 100mL was precisely measured into the solution calorimetry reaction vessel. The solubility of fluconazole in ethanol is $59 \mathrm{mg} / \mathrm{mL}^{15}\left(25^{\circ} \mathrm{C}\right)$, suitable to provide rapid dissolution on breaking the sample ampoule. Six replicates were performed for each polymorph studied. The system was stirred at $500 \mathrm{rpm}$ through rotation of the crushing ampoule mounted in a gold ampoule holder. After setting up 
the vessel the initial temperature offset was targeted to $-250 \mathrm{mK}$ from the measurement temperature, a base line drift with an exponential fit of less than $10 \mu \mathrm{K}$ was established prior to starting the experiment. An electrical calibration of $10 \mathrm{~J}, 500 \mathrm{~mW}$ was performed before and after the sample break. A base line was measured $(5 \mathrm{~min})$ before and after each electrical calibration and before and after the sample break. Data was collected over a 30 min period after the break.

The performance of the system was confirmed using a standard material, tris(hydroxymethyl)aminomethane. ${ }^{16-18}$ TRIS (500.17 mg) was sealed inside a glass breaking ampoule as described previously. The contents were broken into $100 \mathrm{~mL}$ of $0.1 \mathrm{M} \mathrm{HCl}$ (aq.). The heat of solution/reaction for this standard material was measured at $29.640 \mathrm{KJ} \mathrm{mol}{ }^{-1}$ against a reported value of $29.765 \mathrm{KJ} \mathrm{mol}^{-1} .^{17}$

Calculations were performed using Microcal Origin v6.0. Firstly, data was converted from temperature to heat flow using a time constant of $1 \mathrm{sec}$ and an averaging width of $60 \mathrm{sec}$. These values were defined, through trial and error, to provide the best output peak shape. Both calibration points $(10 \mathrm{~J})$ were applied to the data conversion process. The resultant file was exported as an ASCII including time and power values. The ASCII file was imported into Origin and the peak area for all events (calibrations and break) calculated. The data selector tool was used to define the event to be integrated. The base line was automatically calculated and manually fine adjusted within the baseline tool; the area then integrated using the defined baseline option.

The average heat of solution values for the three fluconazole polymorphic forms is detailed in Table S10, this identifying the stability order for the polymorphic forms from most stable AHB $>$ AH-A $>$ AH-C least stable. The full data set is included in Table S11. On integration of the 38 calibration points applied during this study, all returned a peak area of $10.0 \mathrm{~J}$ (std., 0.02 ) providing conformation on the accuracy of the data export and analysis process.

Table S10 Thermodynamic stability of the polymorphic forms of fluconazole at $25^{\circ} \mathrm{C}$.

\begin{tabular}{cccc}
\hline Polymorph & $\begin{array}{c}\text { Heat Solution } \\
(\mathbf{k J} / \mathbf{m o l})\end{array}$ & $\begin{array}{c}\Delta \text { Energy* } \\
(\mathbf{k J} / \mathbf{m o l})\end{array}$ & $\begin{array}{c}\text { Standard } \\
\text { deviation }\end{array}$ \\
\hline AH-A & -26.7 & -1.9 & 0.2 \\
AH-B & -27.8 & -3.0 & 0.2 \\
AH-C & -24.8 & 0.0 & 0.1 \\
\hline
\end{tabular}

$* \Delta$ relative to least stable form, $\mathrm{AH}-\mathrm{C}$ 
Table S11 Calculated peak areas and heat of solution values from solution calorimetry measurements conducted on fluconazole polymorphic forms.

\begin{tabular}{ccccc}
\hline $\begin{array}{c}\text { Sample } \\
\text { Weight (mg) }\end{array}$ & $\begin{array}{c}\text { Calib. 1 } \\
(\mathbf{J})\end{array}$ & $\begin{array}{c}\text { Calib. 2 } \\
(\mathbf{J})\end{array}$ & Break (J) & $\begin{array}{c}\text { Heat Solution } \\
(\mathbf{k J} / \mathbf{m o l})\end{array}$ \\
\hline AH-A & & & & \\
\hline 105.15 & 10.0 & 10.0 & -9.25 & -26.93 \\
104.00 & 10.0 & 10.0 & -9.05 & -26.66 \\
102.95 & 10.0 & 10.0 & -8.97 & -26.68 \\
102.26 & 10.0 & 10.0 & -8.84 & -26.47 \\
103.44 & 10.0 & 10.0 & -8.99 & -26.61 \\
102.68 & 10.0 & 10.0 & -9.03 & -26.93 \\
\hline AH-B & & & & \\
\hline 109.22 & 10.0 & 10.0 & -9.95 & -27.91 \\
110.26 & 10.0 & 10.0 & -10.07 & -27.97 \\
105.50 & 10.0 & 10.0 & -9.55 & -27.74 \\
105.53 & 10.0 & 10.0 & -9.70 & -28.15 \\
102.65 & 10.0 & 10.0 & -9.31 & -27.77 \\
105.56 & 10.0 & 10.0 & -9.49 & -27.53 \\
\hline AH-C & & & & \\
\hline 102.78 & 10.0 & 10.0 & -8.34 & -24.86 \\
102.84 & 10.0 & 10.0 & -8.27 & -24.62 \\
101.00 & 10.0 & 10.0 & -8.23 & -24.96 \\
104.66 & 10.0 & 10.0 & -8.46 & -24.75 \\
104.70 & 10.0 & 10.0 & -8.47 & -24.78 \\
102.91 & 10.0 & 10.0 & -8.37 & -24.91 \\
\hline TRIS & & & & \\
\hline 501.17 & 10.01 & 10.03 & 122.63 & 29.64 \\
\hline
\end{tabular}

\section{References}

1. $\quad$ Basford, P. A.; Back, K. R.; Cram, M.; Docherty, R.; Davey, R. J.; Cruz-Cabeza, A. J., Impact of Crystal Structure and Molecular Conformation on the Hydration Kinetics of Fluconazole. Cryst. Growth Des. 2019, 19, 7193-7205.

2. Groom, C. R.; Bruno, I. J.; Lightfoot, M. P.; Ward, S. C., The Cambridge Structural Database. Acta Crystallographica Section B 2016, 72, 171-179.

3. Caira, M. R.; Alkhamis, K. A.; Obaidat, R. M., Preparation and Crystal Characterization of a Polymorph, a Monohydrate, and an Ethyl Acetate Solvate of the Antifungal Fluconazole. J. Pharm. Sci. 2004, 93, 601-611.

4. Karanam, M.; Dev, S.; Choudhury, A. R., New Polymorphs of Fluconazole: Results from Cocrystallization Experiments. Crystal Growth \& Design 2012, 12, 240-252.

5. Zhu, H.; Grant, D. J. W., Influence of water activity in organic solvent + water mixtures on the nature of the crystallizing drug phase. 2. Ampicillin. Int. J. Pharm. 1996, 139, 33-43. 
6. Zhu, H.; Yuen, C.; Grant, D. J. W., Influence of water activity in organic solvent + water mixtures on the nature of the crystallizing drug phase. 1. Theophylline. Int. J. Pharm. 1996, 135, 151-160.

7. Plus, A., Aspen Plus user guide. Aspen Technology Limited, Cambridge, Massachusetts, United States 2003.

8. Renon, H.; Prausnitz, J. M., Local compositions in thermodynamic excess functions for liquid mixtures. AIChE Journal 1968, 14, 135-144.

9. DIFFRAC.EVA, v4.2.1.10; Bruker AXS GmbH, Karlsruhe, Germany: 2016.

10. DVS Adventure Control Software, v0.106; Surface Measurement Systems Ltd., Unit 5 Wharfside, Rosemont Road, Middlesex, HA0 4PE: 2018.

11. Thompson, S. P.; Parker, J. E.; Potter, J.; Hill, T. P.; Birt, A.; Cobb, T. M.; Yuan, F.; Tang, C. C., Beamline I11 at Diamond: a new instrument for high resolution powder diffraction. Rev Sci Instrum 2009, 80, 075107.

12. Vyazovkin, S.; Burnham, A. K.; Criado, J. M.; Pérez-Maqueda, L. A.; Popescu, C.; Sbirrazzuoli, N., ICTAC Kinetics Committee recommendations for performing kinetic computations on thermal analysis data. Thermochimica Acta 2011, 520, 1-19.

13. Šesták, J.; Berggren, G., Study of the kinetics of the mechanism of solid-state reactions at increasing temperatures. Thermochimica Acta 1971, 3, 1-12.

14. Grimme, S., Semiempirical GGA-type density functional constructed with a long-range dispersion correction. Journal of Computational Chemistry 2006, 27, 1787-1799.

15. Bhesaniya, K.; Nandha, K.; Baluja, S., Thermodynamics of Fluconazole Solubility in Various Solvents at Different Temperatures. Journal of Chemical \& Engineering Data 2014, 59, 649-652.

16. Wadsö, I.; Goldberg, R., Standards in isothermal microcalorimetry (IUPAC Technical Report). Pure and Applied Chemistry 2001, 73, 1625-1639.

17. Rychlý, R.; Pekárek, V., The use of potassium chloride and tris(hydroxymethyl)aminomethane as standard substances for solution calorimetry. The Journal of Chemical Thermodynamics 1977, 9, 391-396.

18. Sabbah, R.; Xu-wu, A.; Chickos, J. S.; Leitão, M. L. P.; Roux, M. V.; Torres, L. A., Reference materials for calorimetry and differential thermal analysis. Thermochimica Acta 1999, 331, 93-204. 